\title{
Implementation of the Three-Phase Induction Machine Model Using Simulink / S-Function
}

\author{
${ }^{1}$ U. Zangina, ${ }^{2}$ Zainab U., ${ }^{2}$ M. I. Ilyasu, ${ }^{2}$ M.A.Yusuf ${ }^{3}$ I. B. Shahu, ${ }^{4}$ I. H. Jibrin \\ and ${ }^{2}$ Abddulbasid I. \\ ${ }^{1}$ Energy Research Centre, Usmanu Danfodiyo University, Sokoto, \\ ${ }^{2}$ Physics/Electrical Departments, Sokoto Polytechnic, Sokoto \\ ${ }^{3}$ Nuhu Bamale Polytechnic \\ ${ }^{4}$ Federal psychiatric Hospital, Kware, Sokoto State
}

\begin{abstract}
In this paper, a generalized induction machine model is implemented using the powerful S-Function (System-Functions) extension capability of the MATLAB/Simulink software package. The model has been formulated by means of the space-phasor notation in which all the three-phase quantities (Voltages, Currents, flux and inductances) are converted to the two-axis $d$-q notation. The dynamic equations of the induction machine are smartly implemented in a single user defined S-Function block, thus addressing the problem of simulation speed when using ordinary Simulink library blocks. The model is then tested in a direct-on-line startup by applying a three-phase ac voltage signal to the machine. Simulation results are presented for a load torque of $10 \mathrm{~N} . \mathrm{m}$ and $40 \mathrm{~N} . \mathrm{m}$ at $t=1 \mathrm{~s}$ to validate the effectiveness of the proposed model.
\end{abstract}

Keywords: Induction machine model, S-Function, Simulink, Simulation speed

\section{Introduction}

Induction machines are popular due to their low-cost, rugged construction, fast pick-up, low maintenance expenditure and good efficiency. With these advantages and the rapid development in computer hardware and software, much research efforts have been invested in developing computer models of the induction machine [1-7].

Matlab/Simulink software package is mostly used by researchers in modeling the induction machine dynamics. This is largely due to its inherent integration of vectorised system representations in block diagram form, its numerical analysis methods, its graphical portrayal of time evolutions of signals and its Graphical User Interface (GUI) for building models which makes it easier and user friendly than other software packages [4]. Most of the induction machine models developed in the literatures use discrete Simulink blocks to represent the machine's dynamic equations $[1,2,3,6]$. Although, this approach is widely used, it has limitations in term of simulation speed [1]. In applications such as Electric Drives where simulation speed is important, the use of SFunction is preferred [1]. With the complexity of the induction machine's nonlinear models, it may be more efficient to represent its equations in a Matlab-File ( $\mathrm{m}$-file) than using ordinary Simulink block. These $\mathrm{m}$-files will be accessed by Simulink through the S-function block. Thus, this method mixes the advantages of an $\mathrm{m}$-file which can be run directly by solvers such as ode45, with the graphical links to other Simulink blocks [8].

In this paper, the S-Function extension capability of Simulink is employed to realize a complete nonlinear model of the three-phase induction machine in a single block diagram. The model developed can be applied in the design of Electric Drive systems.

\section{The Induction Machine Model}

The dynamic behavior of an induction machine is complex due to the coupling effect between the stator and rotor phases [9]. The space-phasor voltage equations of the stator and rotor can be expressed in $\mathrm{d}-\mathrm{q}$ components as $[9,6,10,11]$ :

Voltage equations:

$$
\left[\begin{array}{c}
v_{d s} \\
v_{q s} \\
v_{d r} \\
v_{q r}
\end{array}\right]=\left[\begin{array}{cccc}
R_{s}+s L_{s} & 0 & s L_{m} & 0 \\
0 & R_{s}+s L_{s} & 0 & s L_{m} \\
L_{m} & \omega_{r} L_{m} & R_{r}+s L_{r} & \omega_{r} L_{r} \\
-\omega_{r} L_{m} & s L_{m} & -\omega_{r} L_{r} & R_{s}+s L_{r}
\end{array}\right] \cdot\left[\begin{array}{c}
i_{d s} \\
i_{q s} \\
i_{d r} \\
i_{q r}
\end{array}\right]
$$


Where, $R_{s}$ and $R_{r}$ are the stator and rotor resistances, $L_{s}$ and $L_{r}$ are the stator and rotor self-inductance respectively, $\omega_{s}$ and $\omega_{r}$ are the stator and rotor speed respectively and $L_{m}$ is the mutual inductance.

Flux linkage equations:

$\left[\begin{array}{l}\psi_{d s} \\ \psi_{q s} \\ \psi_{d r} \\ \psi_{q r}\end{array}\right]=\left[\begin{array}{cccc}L_{s} & 0 & L_{m} & 0 \\ 0 & L_{s} & 0 & L_{m} \\ L_{m} & 0 & L_{r} & 0 \\ 0 & L_{m} & 0 & L_{r}\end{array}\right] \cdot\left[\begin{array}{l}i_{d s} \\ i_{q s} \\ i_{d r} \\ i_{q r}\end{array}\right]$

$\psi_{s}$ and $\psi_{r}$ are the stator and rotor flux linkages respectively

The mechanical speed of the induction machine is related to the torque by the following equation:

$T_{e}=T_{L}+\frac{2 J}{p} \frac{d \omega_{r}}{d t}$

Where $T_{e}$ is the electrical Torque, $T_{L}$ is the load torque, $J$ is the combined rotor and load inertia, $p$ is the number of poles and $\omega_{r}$ is the rotor speed.

In terms of the stator and rotor currents, the torque can be written as;

$T_{e}=\frac{3}{2} \frac{p}{2} L_{m}\left(i_{q s} i_{d r}-i_{d s} i_{q r}\right)$

\section{S-Function Implementation}

S-functions (system-functions) provide a powerful mechanism for extending the capabilities of Simulink. It is a computer language description of a Simulink block and can be written in MATLAB, C, C++, Ada, or FORTRAN [8]. One of the most common uses of S-Function is the representation of a dynamic system as a mathematical set of equations. To incorporate an S-function into a Simulink model, the name of the M-file is specified in the user-defined Simulink S-function block from the Simulink library blocks. The parameters specified in the S-Function Parameters field are passed to the corresponding S-Function. An M-file S-function consists of a MATLAB function of the following form [8]:

$[s y s, x o, s t r, t s]=f(t, x, u, f l a g, p 1, p 2, \ldots)$

where $f$ is the S-function name, $t$ is the current time, $x$ is the state vector of the corresponding S-function block, $u$ is the block's inputs, flag indicates a task to be performed, and $p 1, p 2, \ldots$ are the block's parameters.

In the case of this design, the induction machine has four inputs and six outputs. The block parameters $p 1, p 2, \ldots$ are the induction machine parameters specified in section 4. During simulation, Simulink repeatedly invokes $f$, using flag to indicate the task to be performed for a particular invocation. Each time the S-function performs the task, it returns the result in a structure having the format shown in the syntax. The top-level function invokes the sub function indicated by the flag. The standard format for the flags in an S-Function is given in table 1 [8].

Table 1 S-Function Flag routine

\begin{tabular}{|c|c|}
\hline Simulation Stage & Flag \\
\hline Initialization & Flag $=0$ \\
& \\
\hline Calculation of next sample hit & Flag $=4$ \\
\hline Calculation of outputs & Flag $=3$ \\
\hline Update of discrete states & Flag $=2$ \\
\hline Calculation of derivatives & Flag $=1$ \\
\hline End of simulation tasks & Flag $=9$ \\
\hline
\end{tabular}




\section{Simulink Implementation}

The S-Function induction machine model is tested in Simulink as shown in Fig. 4. The three-phase ac voltages are converted to two-phase and vice-versa using the two matrix gain blocks ' $\mathrm{ABC} 2 \mathrm{ab}$ ' and ' $\mathrm{ab} 2 \mathrm{ABC}$ ' respectively.

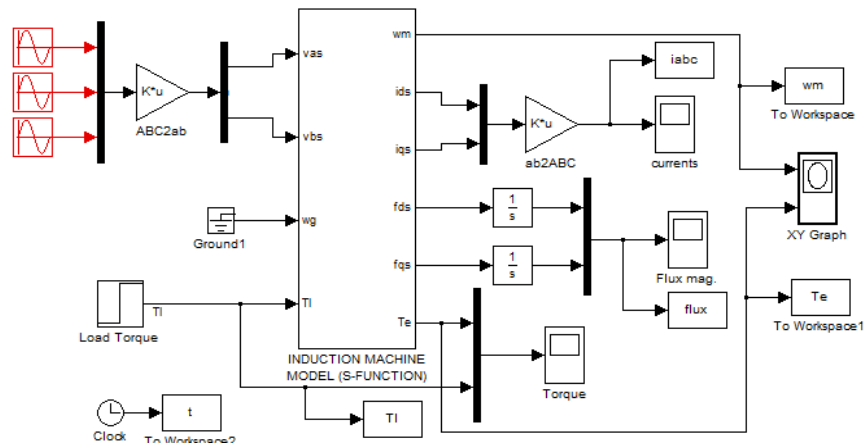

Fig. 4 Induction Machine test model

The three-phase to two-axis transformation is achieved using the equation:

$$
\left[\begin{array}{c}
v_{a s} \\
v_{b s}
\end{array}\right]=\left[\begin{array}{ccc}
1 & -1 / 2 & -1 / 2 \\
0 & \sqrt{3} / 2 & -\sqrt{3} / 2
\end{array}\right]\left[\begin{array}{c}
v_{a} \\
v_{b} \\
v_{c}
\end{array}\right]
$$

\section{Simulation Results}

The induction machine chosen for the simulation studies has the following parameters: Type: Three-phase, 4-pole, squirrel-cage induction motor [4].

$$
\begin{array}{ll}
R_{s}=0.531 \Omega & R_{r}=0.408 \Omega \\
L_{s l}=0.0025 H & L_{r l}=0.0025 H \\
L_{m}=0.085 H & f_{o}=60 H z \\
J=0.1 \mathrm{~kg} / \mathrm{m}^{2} & p=4
\end{array}
$$

To illustrate the transient operation of the induction motor, simulation study of direct-on-line starting is demonstrated. At $t=0$, the motor, previously de-energized and at standstill, is connected to a $220 \mathrm{~V}, 60 \mathrm{~Hz}$ three-phase supply. The load torque, $T_{L}$, is applied at $t=1$. Figures 5 to 10 show the results of computer simulation using the SIMULINK model with $T_{L}=10 \mathrm{~N} . \mathrm{m}$. The results obtained are similar to those obtained in the literatures $[6,1,2]$. In order to assess the improvement in simulation speed, the duration of simulation $\left(t_{\text {sim }}\right)$ is compared with that of a conventional model developed by [2]. 1999. Both models are simulated under the same operating conditions and simulation parameters.
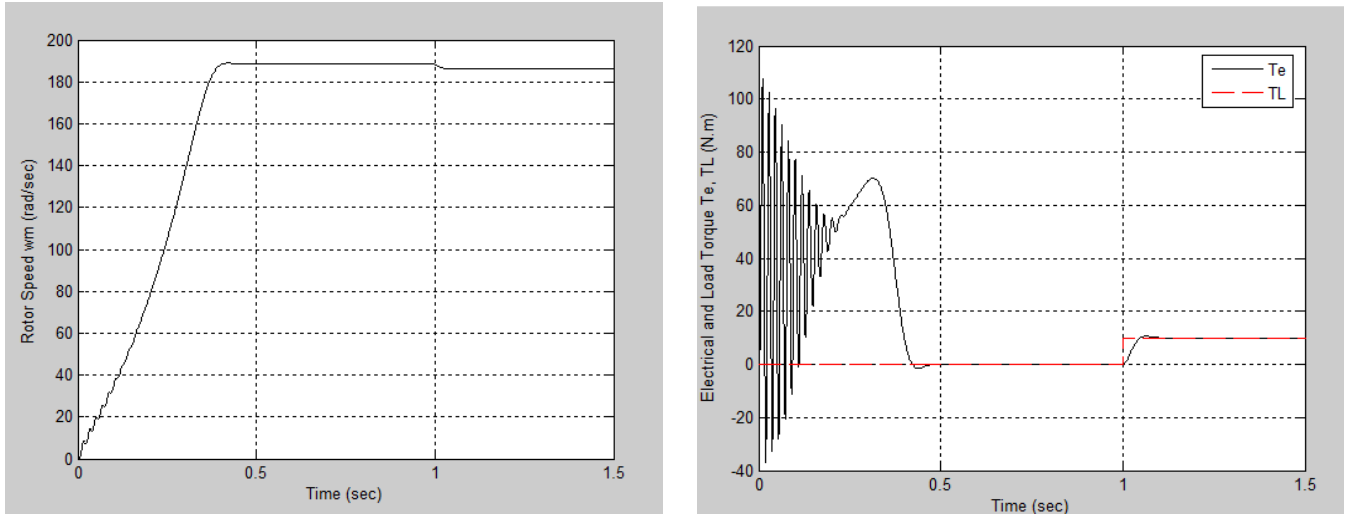
Fig. 5 Rotor Speed (rad/sec)

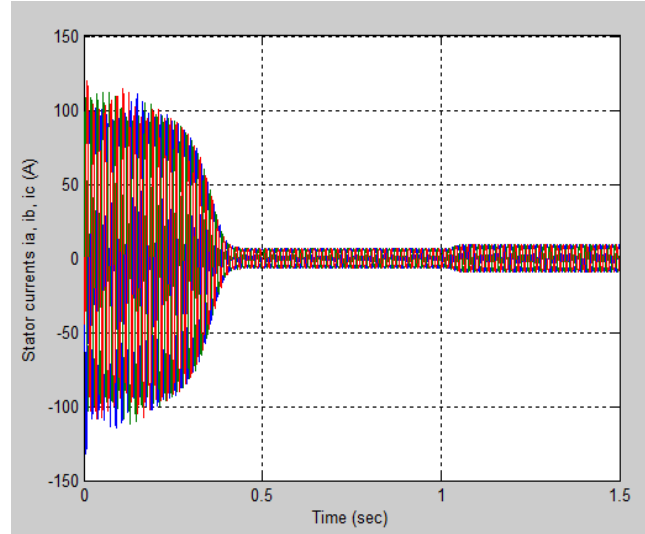

Fig. 7 Stator currents ia ib ic (A)

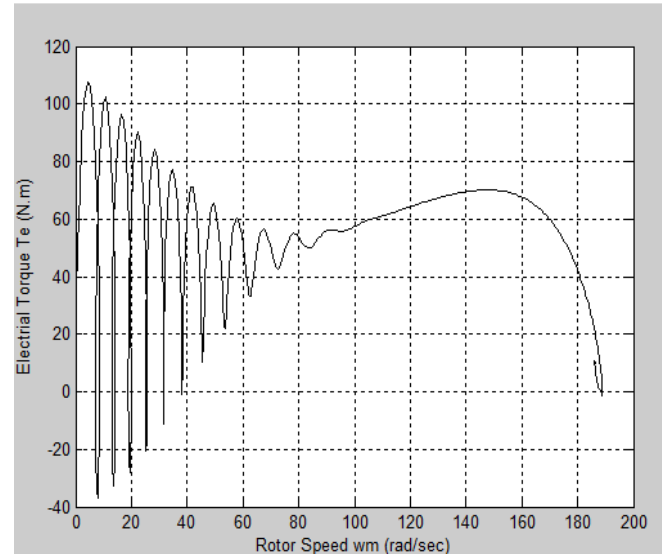

Fig 9 Torque Speed relationship
Fig 6 Motor Torque with Tl=10N.m

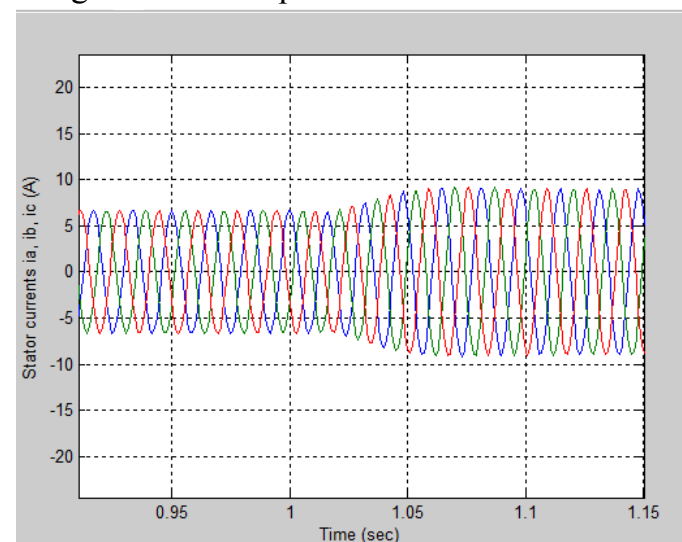

Fig. 8 Zooming the post transient of Fig. 7

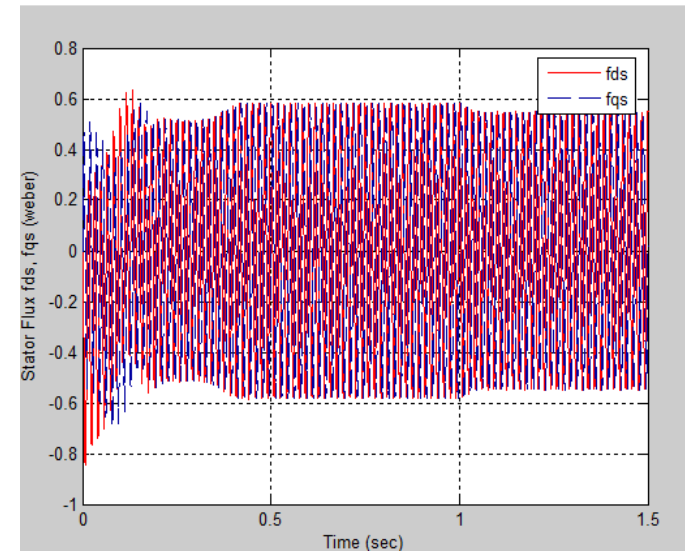

Fig. 10 Stator Flux $f_{d s} f_{q s}$

Table 2: Comparison of simulation speed for $T_{L}=10 \mathrm{~N} . \mathrm{m}$

\begin{tabular}{|l|c|c|}
\hline & S-Function Model & $\begin{array}{c}\text { Conventional } \\
\text { Model }\end{array}$ \\
\hline Simulation period $t_{\text {sim }}(\mathrm{s})$ & 2.26 & 4.10 \\
\hline
\end{tabular}

The machine starts with a small ripple due to transient and settles at the final speed of $187 \mathrm{rad} / \mathrm{sec}$. as shown in Fig. 5. Fig. 6 shows the torque response of the machine. It could be observed that the machine exhibits large torque ripple and settles down to zero in less than 0.5 seconds. A step load torque of $10 \mathrm{~N}$.m is applied at $t=1 \mathrm{~s}$, thus the electrical torque rises and settles to $10 \mathrm{~N} . \mathrm{m}$.

The load torque $T_{L}$ is increased to 40 N.m and the simulation results are shown in Figures 11 to 17. In this case, the speed is less than that of the previous case (with $T_{L}=10 \mathrm{~N} . \mathrm{m}$ ). This is understandable since the load torque has been increased. $T_{e}$ settles to a steady value of 40 N.m as shown in Fig. 11
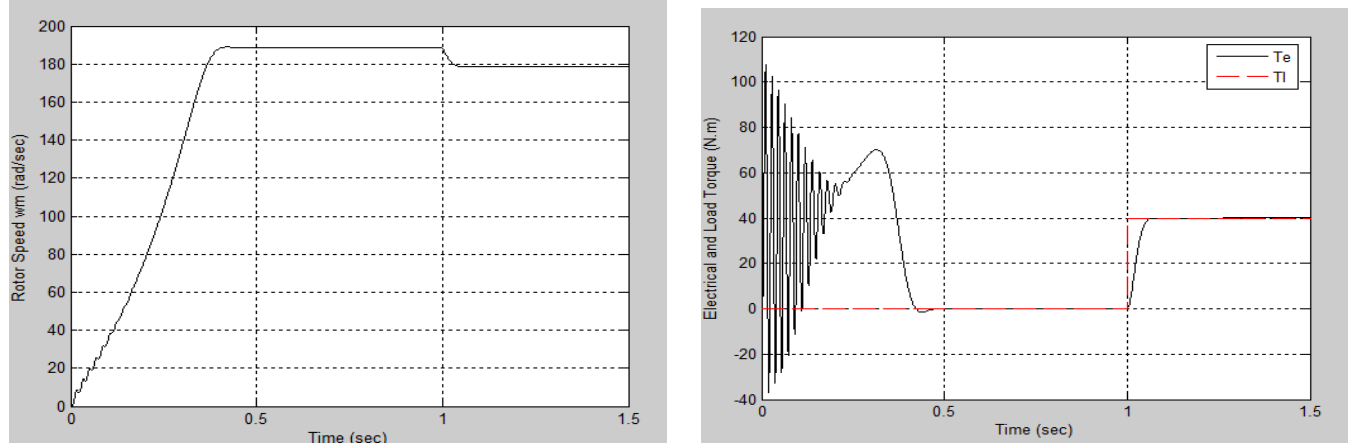
Fig. 1 Rotor Speed (rad/sec)

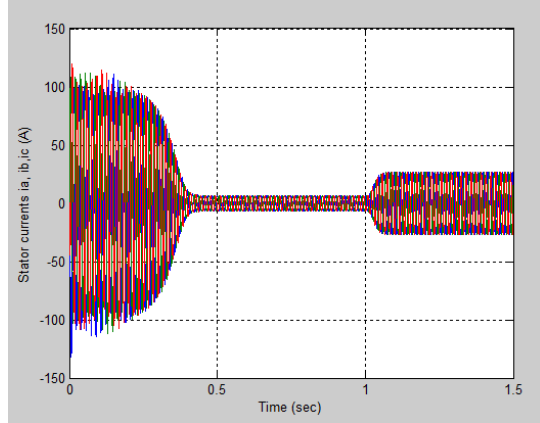

Fig. 12 Motor Torque at $T_{L}=40 \mathrm{~N} . \mathrm{m}$

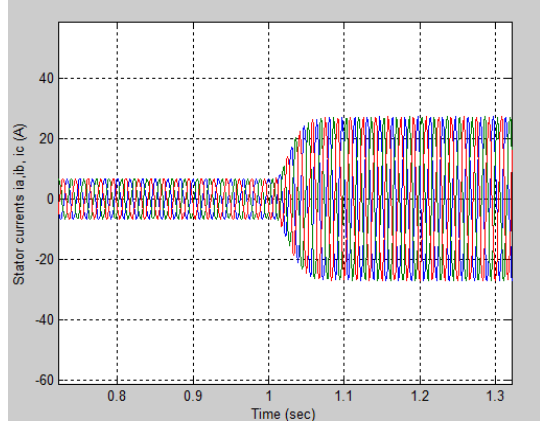

Fig. 14 Zooming the post transient of Fig. 13

Fig. 13 Stator currents ia, ib, ic (A)

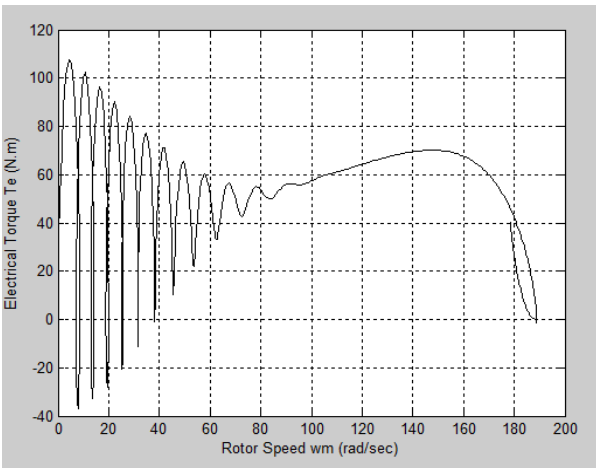

Fig 15 Torque Speed relationship

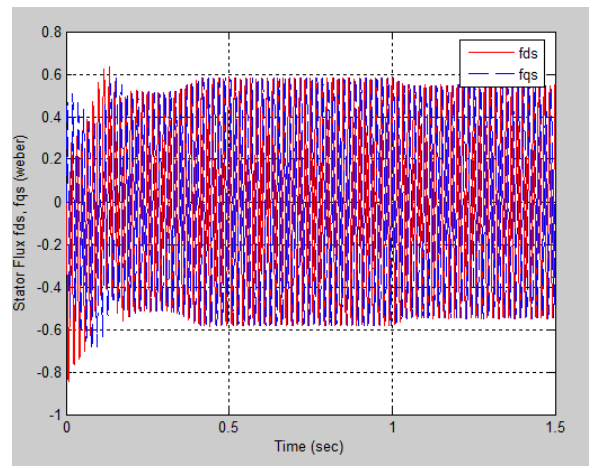

Fig. 16 Stator Flux $f_{d s} f_{q s}$

Table 3: Comparison of simulation speed for $T_{L}=40 \mathrm{~N} . \mathrm{m}$

\begin{tabular}{|l|c|c|}
\hline & S-Function Model & $\begin{array}{r}\text { Conventional } \\
\text { Model }\end{array}$ \\
\hline Simulation period $t_{\text {sim }}(\mathrm{s})$ & 2.65 & 4.78 \\
\hline
\end{tabular}

\section{Conclusion}

In this paper, a complete model of the three-phase induction machine is implemented using S-Function. The model has been formulated by means of the space-phasor notation in which all the three-phase quantities are converted to the two-axis d-q notation. The equations of the machine are written in an $\mathrm{m}$-file which is accesses directly through the S-Function block. This approach has offered two main advantages over the models developed using ordinary Simulink blocks, namely; the simplicity in implementation and enhanced speed of simulation. The model developed in this paper may be used alone, as in the direct-on-line starting example presented, or can be incorporated in advanced Electric Drive systems such as the Field Oriented Control (FOC) and Direct Torque Control (DTC).

\section{References}

[1] B. Ospineci and L.M. Tolbert: Simulink Implementation of Induction Machine Model-A Modular approach, IEEE International Electric machines and drives conference (IEMDC), Vol.2 (2003), pp. 728-734.

[2] K.L. Shi, T.F. Chan, Y.K. Wong and S.L. Ho: Modeling and simulation of the three- phase induction motor using Simulink, International Journal of Electrical Engineering Education, Vol. 36 (1999), pp. 163-172.

[3] S.N. Ghani: Digital computer simulation of three-phase induction machine dynamics, a generalized approach, IEEE Transactions on Industry Applications, Vol. 24, No. 1 (1988), pp. 106-114.

[4] M. Riaz: Simulation of Electric Machines and Drive Systems, University of Minnesota, Department of Electrical and Computer Engineering (2003),Web: http://www.ece.umn.edu/users/riaz.

[5] S. Wade, M.W. Dunnigan and B.M. Williams: Modeling and simulation of induction machine vector control with rotor resistance identification, IEEE Transactions on Power Electronics, Vol. 12, No. 3 (1997), pp. 495-506.

[6] I. Boldea and S.A. Nasar: Electric Drives, CRC Press, Florida, USA, (1998).

[7] H.F. Abdul-Wahab and H. Sanusi: Simulink Model of Direct Torque Control of Induction Machine, American Journal of Applied Sciences Vol. 5 (8) (2008), pp. 1083-1090.

[8] MathWorks: Writing S-Functions, Simulink Toolbox for use with Matlab, the Language of Technical Computing, Version 4, release $12(2000)$.

[9] B. K. Bose: Modern Power Electronics and AC Drives", Prentice-Hall, New Jersey (2002).

[10] P. Vas: Sensorless Vector and Direct Torque Control, Oxford University Press, New York. (1998).

[11] W. Leonhard: Control of Electrical Drives, Springer-Verlag Heidelberg New York. (2001) 